\title{
BUCHBESPRECHUNGEN / BOOK REVIEWS
}

\author{
Tanja Herklotz / Siddharth Peter de Souza (eds.), Mutinies for Equality: Contemporary
}

Developments in Law and Gender in India, Cambridge University Press, Cambridge 2021, 296 pages, EUR 99.00, ISBN 9781108834063.

Gender and law has been the subject of much recent discussion in India. Several activists, academics and lawyers across the country are engaged in work that seeks to challenge the gender-based inequalities that persist in legal doctrine and shape legal institutions. But despite the range of this work (and perhaps because of it), systematic studies of recent developments in the area are rare. Without such systematic studies, it is extremely difficult to keep track of these developments and locate them within larger doctrinal, historical, social and political contexts. This volume takes up this difficult and important task.

'Mutinies for Equality: Contemporary Developments in Law and Gender in India', edited by Tanja Herklotz and Siddharth Peter de Souza and published by Cambridge University Press, records pivotal moments of legal change in the last twenty years in India. These developments are compiled by the editors as representing certain "mutinies" for gender equality that have shaped India's recent past. The contributors use a range of analytic and critical frames to make sense of these mutinies - reflecting on the power of transformative efforts and, at some of the strongest moments of the book, on their deep limitations.

The volume is divided into three sections. The first section deals with the areas in which systems of inequality persist in legal doctrine and institutions in the country. The second section contains chapters that investigate battles for equality or the moments in India's legal past where unequal systems were challenged. The third section discusses the challenges faced in realising equality - challenges that can provide important points of reflection for the future.

The chapters in the first section all deal with some system of inequality in India's legal system. The systems that the volume discusses seem to largely be of two types: substantive and procedural. The substantive systems of inequality refer to areas of doctrinal law that continue to treat certain social groups unfairly and perpetuate structural inequality. FritziMarie Titzmann's chapter on the law relating to obscenity and Katharina Wommelsdorff's chapter on the law regarding triple talaq serve as examples of this - highlighting gaps and inequalities in these specific areas of law. Krithika Ashok's chapter breaks new ground in thinking of gender inequalities that persists in systems of property law: a doctrinal area that has been understudied by scholars of gender and law in India.

To supplement this analysis of substantive systems of inequality, there are two chapters that reflect upon procedural and institutional failures of the judiciary. Jayna Kothari's argument that the Supreme Court "cherry picks" its gender battles importantly flags a common and intuitive discomfort with the selective approach taken by the Apex Court to gender-based issues. This "cherry-picking" seems to be a theme in later parts of the volume 
as well and merits further examination. Siddharth Peter de Souza and Medha SrivastavaKehrer's chapter throws light on another systemic issue with the judiciary, that helps us see that the constitution of benches in the Apex court could be a reason for its selective approach to the issues of gender and law that Kothari identifies. Even if the constitution of the bench does not have a direct impact on the verdicts issued, the intersectional approach to judicial appointments suggested by De Souza and Srivastava-Kehrer paves the way for a more diverse composition of judges in India's judicial system.

The volume moves then from looking at these persisting systems of inequality to focussing on the battles against these systems. Chapters in this section discuss instances where litigants, both individually and collectively, have challenged unequal systems. There are those chapters that deal rigorously with important questions about legal doctrine and their unequal societal effects: Saumya Saxena's chapter on nikah halala, Sameena Dalwai's work on bar dancing and Mandira Kala's article on surrogacy. Other chapters, I think, complicate the very idea of a "mutiny for equality" itself. Both Saptarshi Mandal and Tanja Herklotz centralise the litigant in their construction of a battle or mutiny for equality - the single mother in Mandal's chapter, and the three women litigants that Herklotz places at the crux of transformative efforts. The litigants are at the centre of the story in both these essays. This method of legal writing, told through the voice of litigants, finds most eloquent reflection in Herkloz and Mandal's writings and is a truly memorable narrative strategy. Additionally, Jason Keith Fernandes's chapter on queer liberation employs a critical lens with which to look at the idea of "mutinies" and transformation. By noting the importance of the Navtej Singh Johar v. Union of India judgment in a struggle for equality and its simultaneous shortcomings, the author highlights the deep limitations of legal reform in majoritarian political and social contexts.

Finally, the third section of the volume addresses the struggles faced in the process of realising equality. The chapters in this section of the book move from the realm of the legal to the social - dealing with the challenges faced in realising equality at a societal level. Sourav Mandal poignantly articulates the social pressure that queer people face to abide by heteronormative standards and throws light on how they navigate complex heteronormative frameworks, present both in legal systems and in societal kinship patterns. The volume concludes with two chapters by Kalindi Kokal and Poornima Hatti and Aparna Ravi that deal with issues that women's groups face at the grassroots with dispute resolution. Both chapters look at dispute resolution mechanisms that are different from litigation - community mediation and the internal complaints mechanism at workplaces in sexual harassment cases - and analyse the efficacy of these processes in comparison with litigation. The chapters in this section of the book thus go beyond the realm of the legal, in a strict sense, and engage with how rules and dispute resolution processes outside of the realm of litigation contribute to the struggles in the process of realising equality.

The volume deals with systems of inequality and the battles to eradicate these systems, pointing also to the deep-rooted socio-political and cultural challenges in the way of achieving equality. While the editors mention towards the end of the introduction that there is "no 
linear process from inequality towards equality", I found that this linearity was inherent in some of the ways that the volume was structured. The idea reflected in the structure of the book, that some struggles have been "successful" in realising equality, and some have not, assumes in part that equality can be clearly achieved. It assumes at the very least that some battles have been successful, while in other areas inequality still persists. But can we really speak of transformative efforts as either "succeeding" or "failing" in achieving equality?

The editors are certainly cognisant of this complexity (even if they cannot avoid it) when they note that "success" and "failure" are hard to define and distinguish. In line with this, it is worth asking how we should approach social transformation in the area of law and gender. If it is equality that we are aspiring for, can we say, with clarity, that it has been achieved in any area - however small? Or if the idea is that equality can be achieved in some areas, only to give rise to new inequalities, then the editors suggestion that transformation requires constant "fuelling and maintaining" is compelling.

'Mutinies for Equality' studies transformative efforts in the area of law and gender. It helps make sense of these efforts and locates them against an important historical, social and cultural backdrop. But the volume also provokes new areas of inquiry. If the process from inequality to equality is not linear, but is more complex, what should our actions be oriented towards? How do we understand our own processes? What goals should our series of "doings" seek to achieve? This volume opens up these - and several other - important questions.

Readers of the volume may thus find that the volume strikes a rare balance: between detailed description and critical evaluation. Legal developments are recorded, but are also assessed for what they did (and very often did not) achieve. This balance, between describing focal points in our collective histories and evaluating these moments with honest criticality, makes the volume an invaluable addition to the scholarship on gender and law in India.

Ira Chadha-Sridhar 